\title{
Ancient Records and Modern Research on the Mechanisms of Chinese Herbal Medicines in the Treatment of Diabetes Mellitus
}

\author{
Hai-ming Zhang, ${ }^{1}$ Feng-xia Liang, ${ }^{2}$ and Rui Chen ${ }^{1}$ \\ ${ }^{1}$ Department of Traditional Chinese Medicine, Union Hospital, Tongji Medical College, \\ Huazhong University of Science and Technology, No. 1277 Jiefang Street, Wuhan, Hubei 430022, China \\ ${ }^{2}$ Department of Acupuncture and Moxibustion, Hubei University of Traditional Chinese Medicine, \\ No. 1 Tanhualin Street, Wuhan, Hubei 430060, China
}

Correspondence should be addressed to Feng-xia Liang; fxliang@hotmail.com and Rui Chen; unioncr@163.com Received 15 March 2014; Accepted 25 June 2014

Academic Editor: Srinivas Nammi

Copyright (C) 2015 Hai-ming Zhang et al. This is an open access article distributed under the Creative Commons Attribution License, which permits unrestricted use, distribution, and reproduction in any medium, provided the original work is properly cited.

Over the past decades, Chinese herbal medicines (CHM) have been extensively and intensively studied through from both clinical and experimental perspectives and CHM have been proved to be effective in the treatment of diabetes mellitus (DM). This study, by searching ancient records and modern research papers, reviewed CHM in terms of their clinical application and principal mechanism in the treatment of DM. We summarized the use of CHM mentioned in 54 famous ancient materia medica monographs and searched papers on the hypoglycemic effect of several representative CHM. Main mechanisms and limitations of CHM and further research direction for DM were discussed. On the basis of the study, we were led to conclude that TCM, as a main form of complementary and alternative medicine (CAM), was well recorded in ancient literatures and has less adverse effects as shown by modern studies. The mechanisms of CHM treatment of DM are complex, multilink, and multitarget, so we should find main hypoglycemic mechanism through doing research on CHM monomer active constituents. Many CHM monomer constituents possess noteworthy hypoglycemic effects. Therefore, developing a novel natural product for DM and its complications is of much significance. It is strongly significant to pay close attention to CHM for treatment of DM and its complications.

\section{Introduction}

Diabetes mellitus (DM), including type 1 and type 2, has become epidemic worldwide [1-3], and its incidence has been on rise year by year [4]. Previous reports have demonstrated that overweight, especially obesity at younger ages, substantially increases the risk for DM $[1,5-8]$. The finding is consistent with the description in the "Medical Classic of the Yellow Emperor," the earliest monumental work on the traditional Chinese medicine (TCM) dating back to the Warring States Period (about 446 B.C. -221 B.C.). DM increases the risk for micro- and macrovascular complications and premature death and poses tremendous socioeconomic burden $[2,4,9]$. In spite of the introduction of insulin and other hypoglycemic agents, so far, no treatment protocols can achieve a complete cure. Moreover, the side effects of these drugs, which are substantial and inevitable, present another challenge.
Complementary and alternative medicine (CAM) have been extensively used in modern times. TCM, as a main form of CAM, has been proved to be effective for the treatment of DM with relatively less side effects in China and beyond $[10,11]$. Some hypoglycemic drugs of plant origin have been approved for clinical use by the regulatory authorities in China, such as Yusanxiao, Yijin, and Kelening, among others [12].

The mechanisms of Chinese herbal medicines (CHM) in the treatment of DM have been extensively and intensively studied from biological, immunological, and phytochemical perspectives and great advances have been made in the past decades. This paper reviewed records or descriptions concerning the use of CHM for treatment of DM in ancient Chinese literatures (before 1920 A.D.) and the modern papers on the mechanisms of CHM treating DM. We also compared the CHM used in ancient and modern times, examined the 
TABLE 1: A similar comparison of the symptoms of "Xiao Ke" and DM.

\begin{tabular}{|c|c|c|}
\hline & Symptoms of "Xiao Ke" in Zhu Bing Yuan Hou Lun ${ }^{a}$ & Symptoms of DM in Textbook of Internal Medicine [22] \\
\hline $\begin{array}{l}\text { General } \\
\text { symptoms }\end{array}$ & $\begin{array}{l}\text { Polydipsia; dry mouth and lips; polyphagia; hunger; } \\
\text { emptiness of the stomach; frequent urination; polyuria; } \\
\text { glucosuria; emaciation; adiposity; fatigue of limbs; } \\
\text { mental fatigue; feverish dysphoria; itchy skin; } \\
\text { hyperhidrosis; dizziness; sweet feeling in the mouth. }\end{array}$ & $\begin{array}{l}\text { Polydipsia; thirst; polyphagia; hunger; polyuria; } \\
\text { marasmus; obesity; sweet taste of urine; itchy skin; } \\
\text { vulva pruritus; fatigue; lightheadedness. }\end{array}$ \\
\hline Complications & $\begin{array}{l}\text { Carbuncle and soreness; night blindness; internal } \\
\text { oculopathy; lung tuberculosis; edema; precordial pain; } \\
\text { pectoral stuffiness pain; apoplexy; coma; impotence; } \\
\text { foot carbuncle-abscess; unsmooth defecation; diarrhea; } \\
\text { anorexia; short breath; waist soreness; dizziness and } \\
\text { tinnitus; pachylosis; whitish and turbid urine; muscle } \\
\text { atrophy of the lower extremities; oliguria; nightly } \\
\text { sweating; coolness of extremities. }\end{array}$ & $\begin{array}{l}\text { Carbuncle and furuncle; diabetic retinopathy; } \\
\text { pulmonary tuberculosis; diabetic cardiomyopathy; } \\
\text { diabetic ketoacidosis; diabetic impotence; glaucoma; } \\
\text { diabetic nephropathy; atherosclerosis; cerebral } \\
\text { ischemic stroke; diabetic foot; constipation; diarrhea; } \\
\text { myophagism; paralysis; oliguria; hyperhidrosis; } \\
\text { hypohidrosis or anhidrosis; diabetic gastroparesis. }\end{array}$ \\
\hline
\end{tabular}

aThe "Zhu Bing Yuan Hou Lun": a book describing causes and manifestations of diseases by Yuanfang Chao, a famous TCM doctor born about AD 550 and died in 630 A.D. in the Sui Dynasty.

limitations of CHM for treating DM, and discussed the future research trend.

\section{Ancient Records on Treatment of DM with TCM}

Our search of literatures of TCM (before 1920 A.D. or earlier) failed to find the term "DM." We found a plenty of records or descriptions about "Xiao Ke," which, in terms of epidemiology, symptoms, etiology, pathogenesis, and treatment, mimicked those of DM. And it is generally accepted that "Xiao Ke" mentioned in ancient Chinese literature is similar to DM of modern medicine [13]. On basis of this assumption, in this paper, we used DM interchangeably with "Xiao Ke" for the convenience of discussion though they are not strictly equivalents in a number of ways.

\subsection{Terminology, Epidemiology, Symptoms, Etiology, and Pathogenesis of "Xiao Ke"}

2.1.1. Name. In TCM, "Xiao Ke" refers to a cluster of clinical symptoms, including polydipsia, polyphagia, polyuria, emaciation, glucosuria, and fatigue. As aforementioned, "Xiao $K e$ " is a general term for a condition that resembles DM in terms of symptoms. DM classically was divided into three types: upper, middle, and lower "Xiao Ke." The upper type (Shang Xiao) is characterized by excessive thirst, the middle type (Zhong Xiao) by excessive hunger, and the lower type (Xia Xiao) by excessive urination [13]. By searching "Xiao Ke," we retrieved a large number of records concerning "Xiao Ke" in ancient TCM literatures.

2.1.2. Epidemiology. The earliest mention of "Xiao Ke" was in the "Medical Classic of the Yellow Emperor." The book described that the "Xiao Ke" was mostly found in wealthy, obese individuals who liked food rich in oil or fat and in influential officials who were on pills or "Dan," as it was termed in the book, a mineral-based synthetic drug, which ancient people believe to be able to make them achieve longevity.

2.1.3. Symptoms. The symptoms can be categorized into two groups: general symptoms and complications. The general symptoms include polydipsia, polyphagia, polyuria, glucosuria, emaciation, dry mouth, hunger, emptiness of the stomach, and frequent urination. And complications include diabetic foot, diabetic retinopathy, lung tuberculosis, diabetic impotence, and diabetic nephropathy. Obviously, those symptoms and complications are extremely similar to DM, as shown in Table 1.

2.1.4. Etiology and Pathogenesis. According to the theory of TCM, the symptoms are essentially caused by "Yin $X u$ " (Yin deficiency) and "Zao Re" (dryness heat). In TCM there is a belief that Yin deficiency is the "Ben" (origin or root cause) and dryness heat is the "Biao" (symptoms or external manifestations). The Ben or root causes involve the invasion of exogenous pathogens, innate deficiency, intemperance in eating, abnormal emotional states (anger, anxiety, depression, distress, panic, and fear), excessive physical strains (mental or physical exertion and sexual intercourse), or propensity for abusing Dan medicines [11]. Yin and Yang are two opposing aspects of things. For instance, cold, moist, night, structure, and downward mobility belong to Yin while heat, dryness, day, function, and upward mobility belong to Yang [14].

2.2. Treatment. We searched for the term "Xiao Ke" in more than 1,000 TCM ebooks included in Encyclopedia of TCM (Compact Disk, ISBN: 7-900377-49-2/R·8), published by Hunan Electronic and Audiovisual Publishing House. The database contained, among others, "Bencao Gangmu (Compendium of Materia Medica)", Puji fang, and so forth.

2.2.1. CHM. We also searched the database for Chinese crude drugs for treating "Xiao Ke." The database contained only 54 monographs on Chinese materia medica. Most CHM treated "Xiao Ke" by "Qing Re" (clearing heat) (Figure 1), 


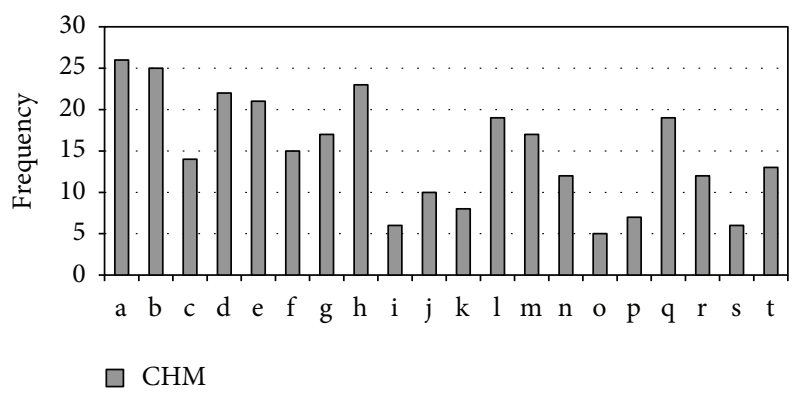

FIGURE 1: Frequency of heat-clearing (Qing Re) drugs for "Xiao Ke" mentioned in 54 monographs on Chinese materia medica. Heatclearing drugs are of Liang (cold or cool) or bitter taste. a: Pueraria lobata (Willd.) Ohwi; b: Trichosanthes kirilowii Maxim.; c: Fructus et semen trichosanthis kirilowii; d: Lemna minor L.; e: Gypsum fibrosum; f: Alisma orientale (Sam.) Juz.; g: Coptis chinensis Franch.; h: Anemarrhena asphodeloides Bunge; i: Lophatherum gracile Brongn.; j: Succus bambusae (Recens); k: Arctium lappa L.; l: Phragmites australis (Cav.) Trin. ex Steud.; m: Benincasa hispida (Thunb.) Cogn.; n: Phaseolus calcaratus Roxb.; o: Scutellaria baicalensis Georgi; p: Solanum lyratum Thunb.; q: Vitex negundo var. cannabifolia (Siebold and Zucc.) Hand.-Mazz.; r: Phellodendron chinense C. K. Schneid.; s: Gardenia jasminoides J. Ellis; t: Lycium chinense Mill.

"Yang Yin" (nourishing Yin), and "Yi Qi" (replenishing vital energy) (Figure 2). The Latin names of CHM used in the paper were from the website http://www.theplantlist.org/ or http://www.wikipedia.org/.

2.2.2. Foods. Besides, the monographs also mentioned some foods that help treat "Xiao Ke" in Figure 3.

\section{Mechanisms by Which CHM Work on DM and Its Complications}

We searched the databases of PubMed, Web of Science, MEDLINE, and CNKI and found that less research attention was paid to Chinese herbal compounds while most studies focused on a single herbal medicine.

The mechanisms of CHM in the treatment of DM have been extensively and intensively studied from biological, immunological, and phytochemical perspectives (Tables 2, 3, and 4).

\section{Results}

We found more than 40 CHM with hypoglycemic effect in ancient works and reviewed the mechanism of $\mathrm{CHM}$ lowering blood sugar. We were led to conclude that a number of CHM, including Panax ginseng C. A. Mey., Astragalus membranaceus (Fisch.) Bunge, and Lonicera japonica Thunb., were used in ancient times and also nowadays. In addition, some CHM used for treating DM in ancient works have not been studied for hypoglycemic effect in modern times, such as Lemna minor L., Gardenia jasminoides J. Ellis, Eleocharis dulcis (Burm.f.) Trin. ex Hensch., and Achyranthes bidentata Blume (Figures 1 and 2). These CHM may have potential to

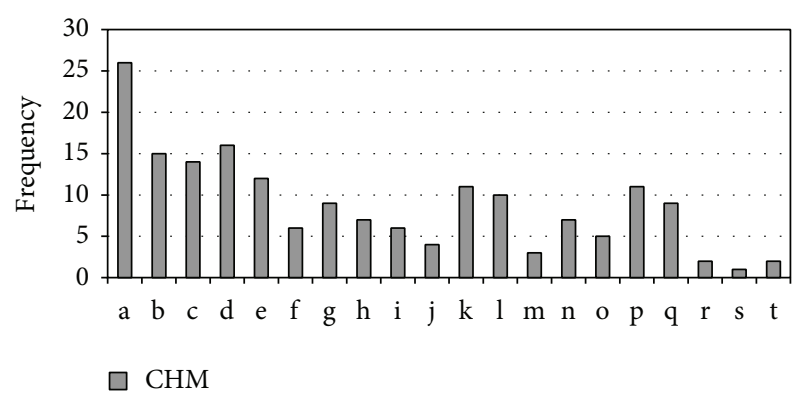

FIGURE 2: Frequency of Yin-nourishing (Yang Yin) and energyreplenishing (Yi Qi) drugs for "Xiao Ke" mentioned in 54 monographs on Chinese materia medica. Yin-nourishing and energyreplenishing drugsare of sweetish taste and are of cold (Liang) nature. a: Lycium barbarum L.; b: Tussilago farfara L.; c: Poria cocos (Schw.) Wolf; d: Panax ginseng C. A. Mey.; e: Eleocharis dulcis (Burm.f.) Trin. ex Hensch.; f: Morus alba L.; g: Adenophora trachelioides Maxim.; h: Cannabis sativa L.; i: Ophiopogon japonicus (Thunb.) Ker Gawl.; j: Armeniaca mume Siebold; k: Asparagus cochinchinensis (Lour.) Merr.; l: Cuscuta chinensis Lam.; m: Achyranthes bidentata Blume; n: Coix lacryma-jobi L.; o: Astragalus membranaceus (Fisch.) Bunge; p: Polygonatum odoratum (Mill.) Druce; q: Rhus chinensis Mill.; r: Schisandra chinensis (Turcz.) Baill.; s: Lilium lancifolium Thunb.; t: Rehmannia glutinosa Steud.

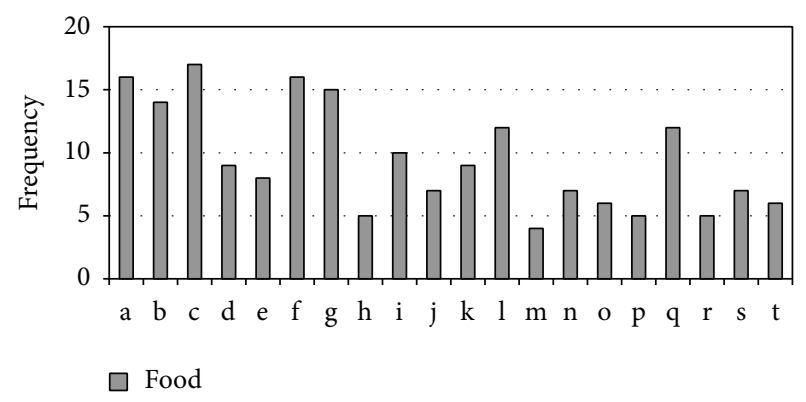

FIGURE 3: Frequency of meat, grains, fishes, and other food that help treat "Xiao Ke" mentioned in 54 monographs on Chinese materia medica. a: chicken; b: millet; c: barley; d: bamboo shoot; e: cony meat; f: Benincasa hispida; g: watershield leaf; h: mud eel; i: radish; j: foxtail millet seed; k: snail; l: cow's milk; m: goose meat; n: Charr; o: long surf clam; p: wheat; q: mung bean; r: Gallus black-bone silky fowl; s: hairy chestnut seed; t: giant gecko.

become drugs for the treatment of DM by further exploring their hypoglycemic effects. We also found that some foods were used for treatment of DM in ancient times, and their hypoglycemic effects have been confirmed nowadays $[15,16]$.

The mechanisms by which CHM treat diabetes include the following: (1) $\mathrm{CHM}$ increase insulin sensitivity and ameliorate insulin resistance; (2) CHM promote insulin secretion and elevate serum insulin levels; (3) CHM inhibit $\alpha$-glucosidase activity; (4) CHM protect islet $\beta$ cells and promote their regeneration; (5) CHM increase hepatic glycogen content and suppress gluconeogenesis; (6) CHM inhibit the secretion of glucagon; (7) CHM promote the glucose uptake by adipose and muscular tissues (Figure 4). Mechanisms of $\mathrm{CHM}$ treating diabetic complications include the following: 


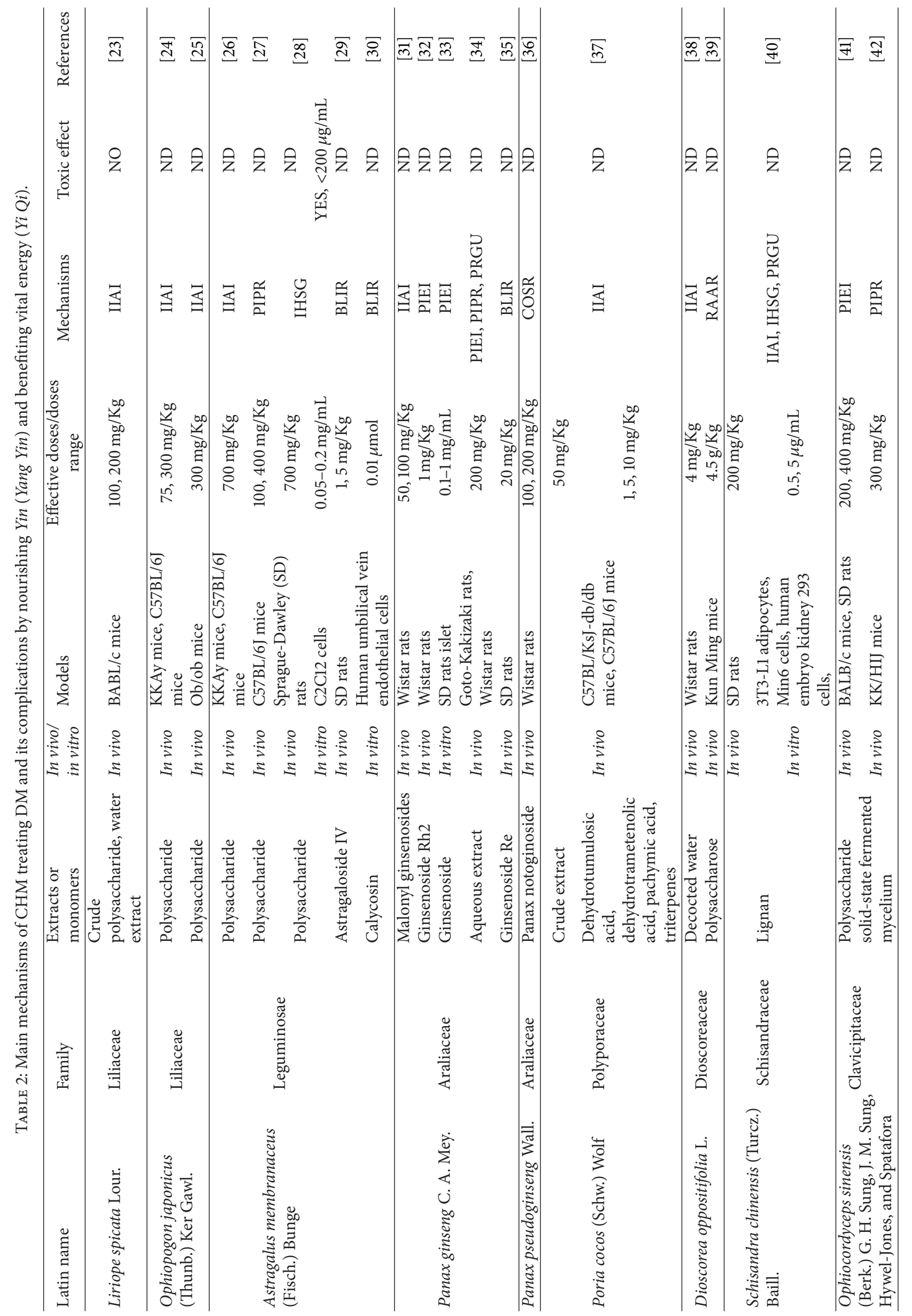




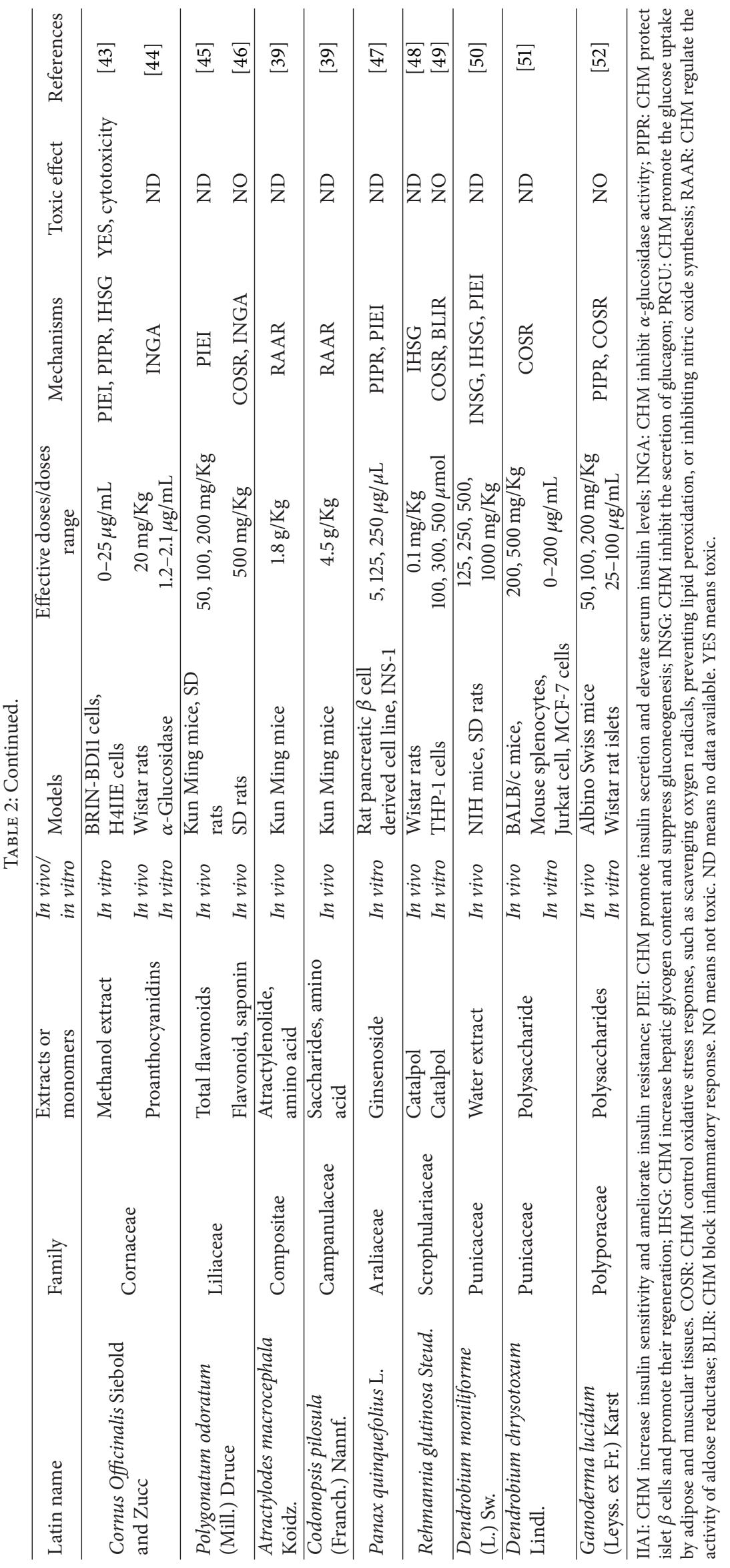




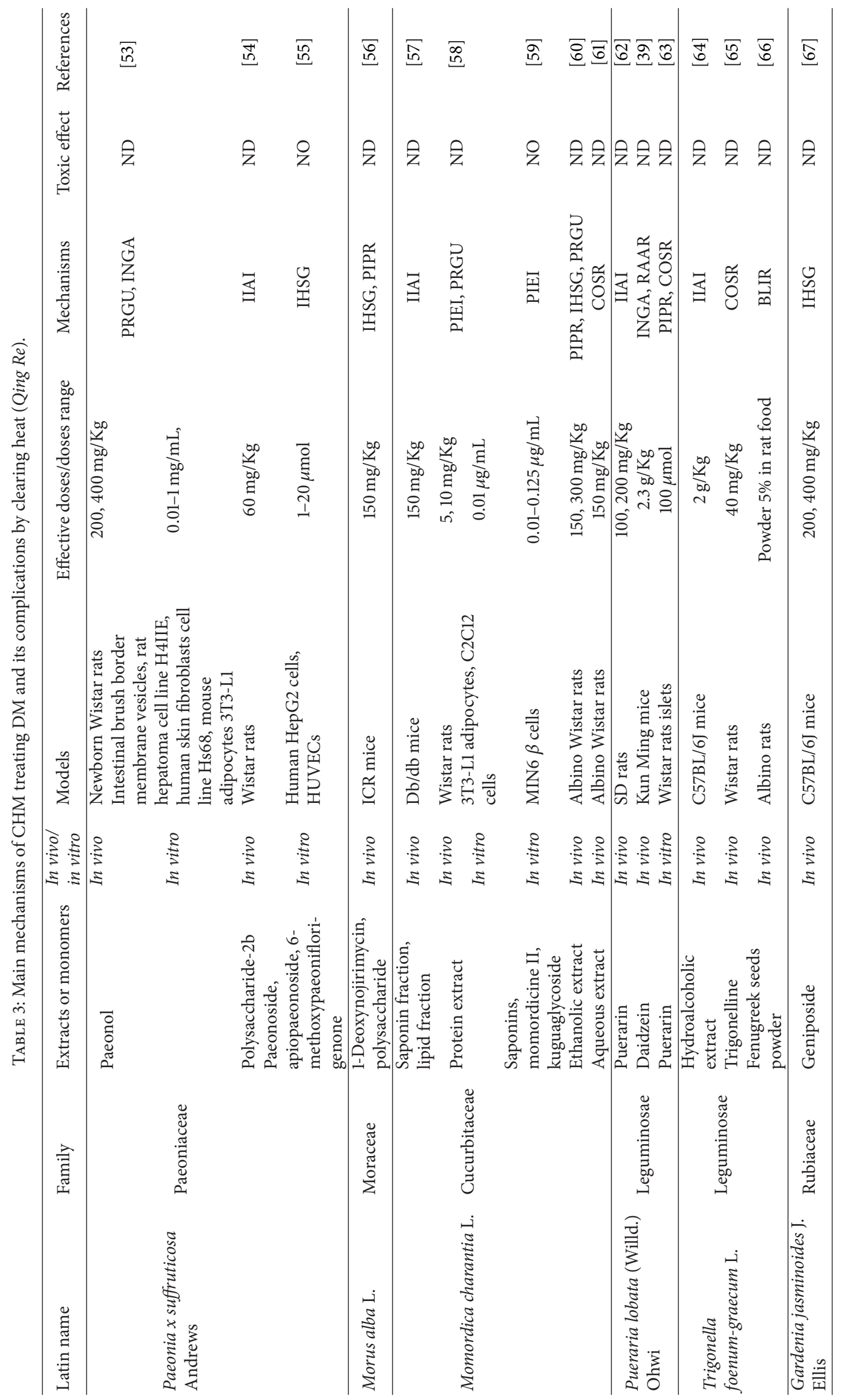




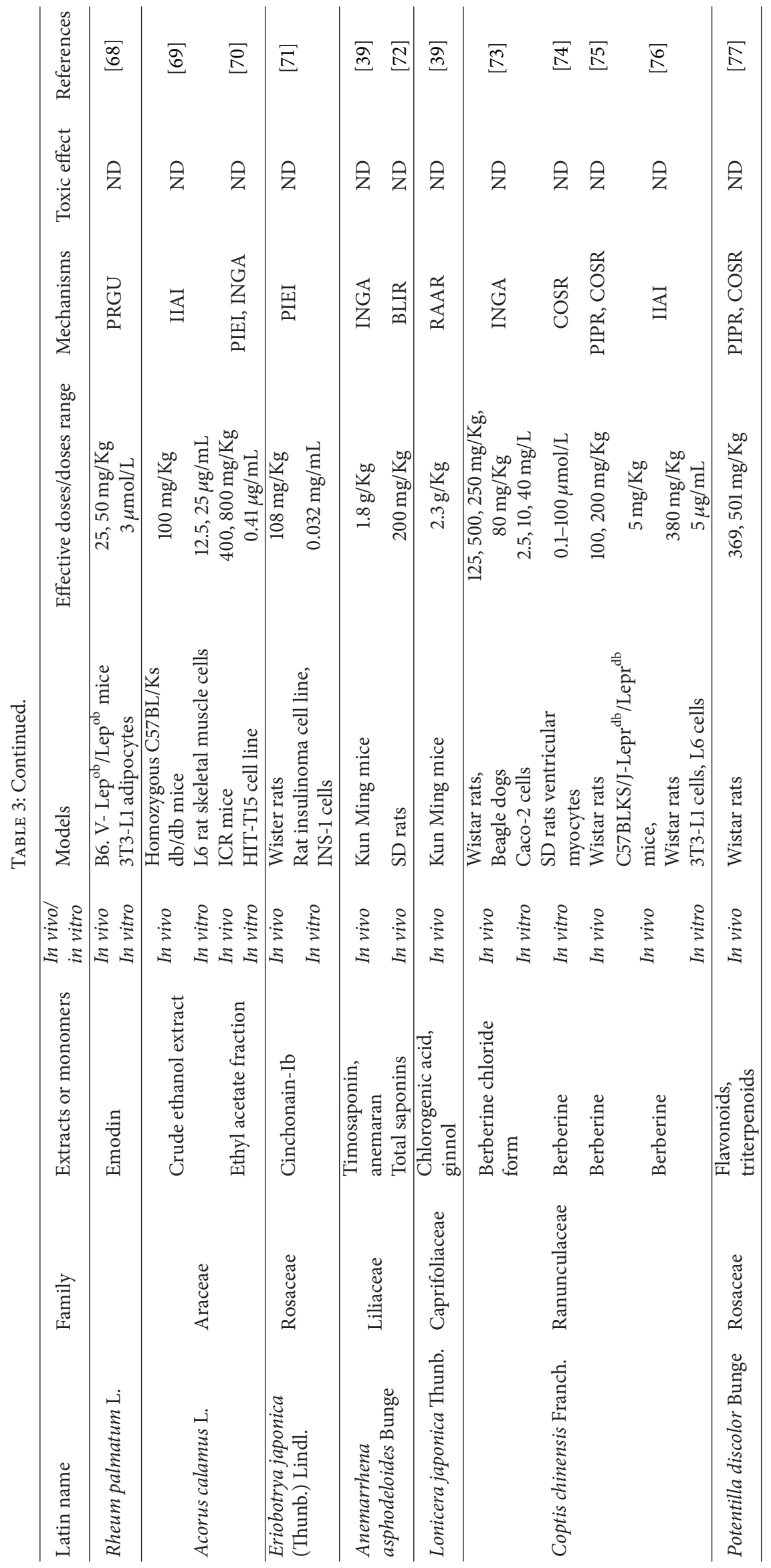




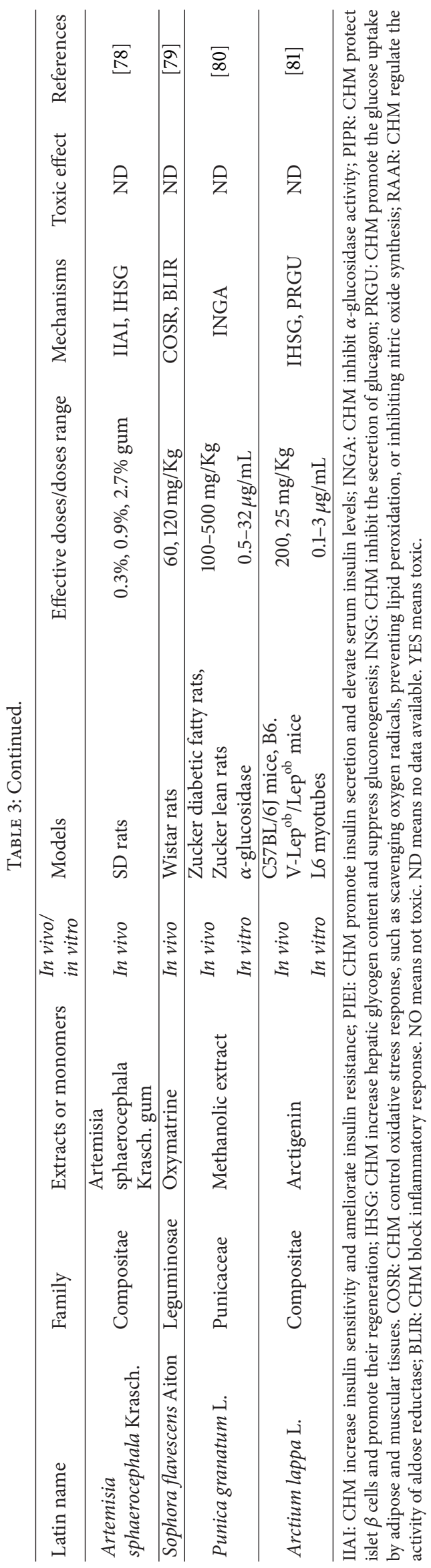




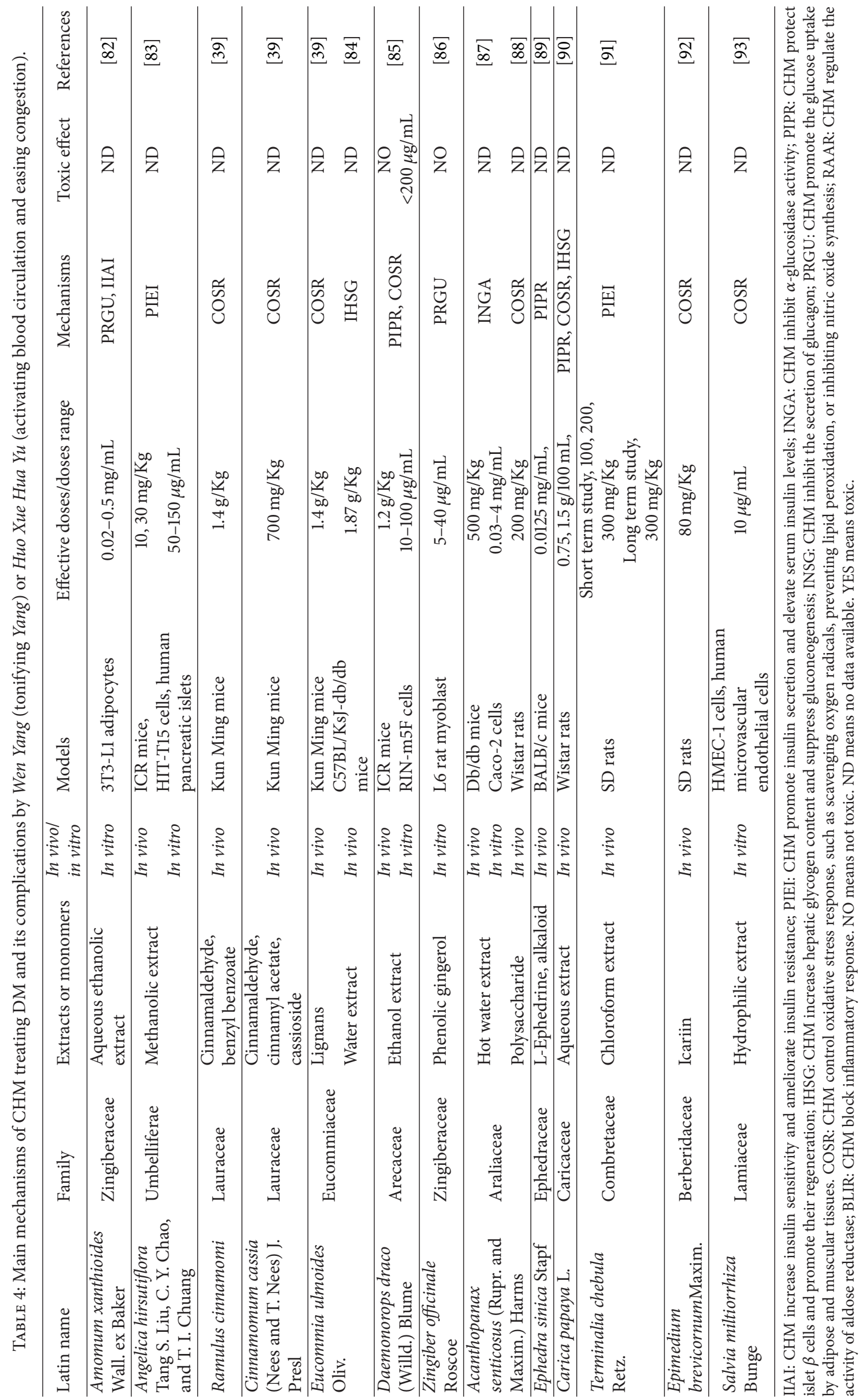




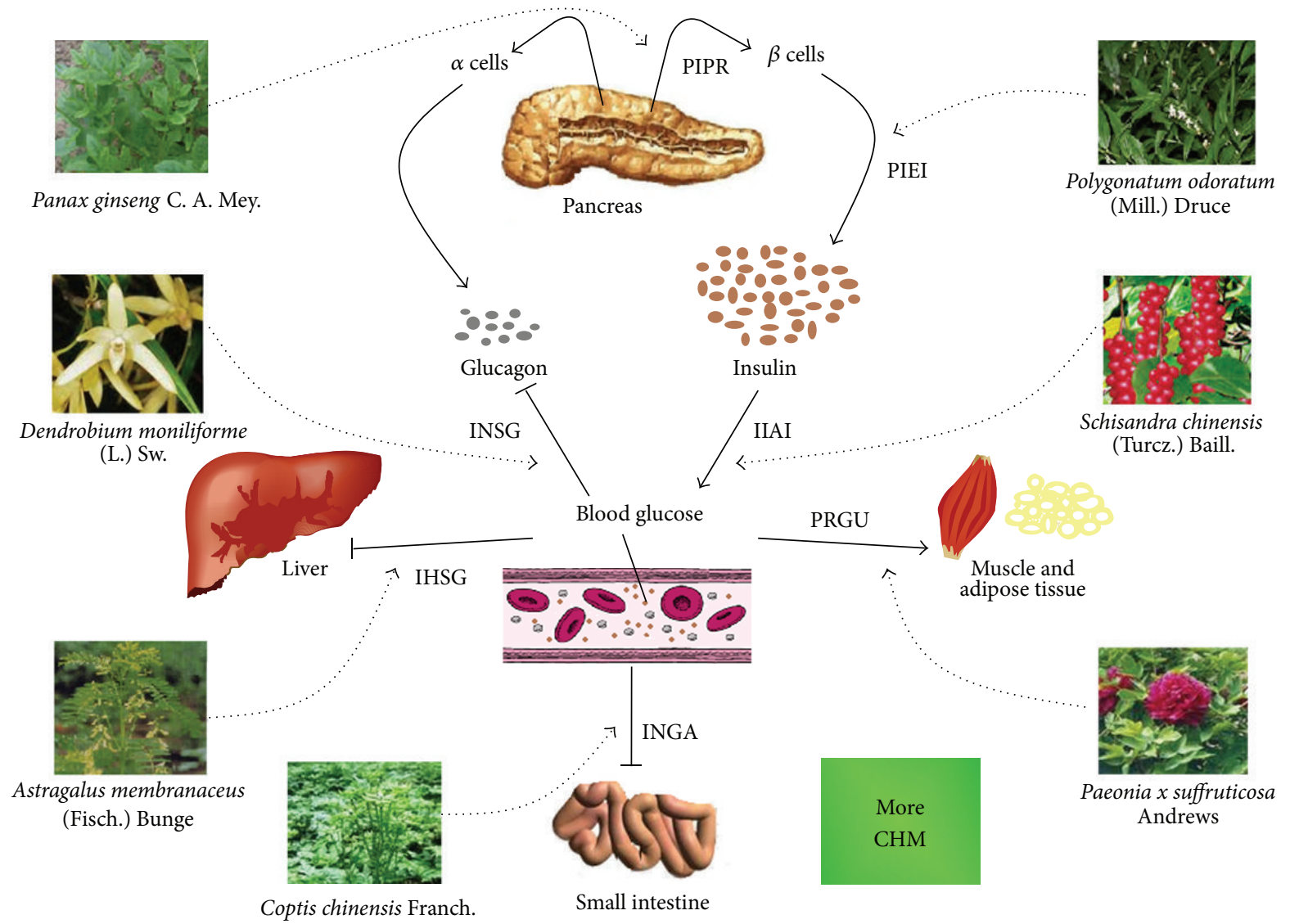

FIGURE 4: Main mechanisms of CHM working on DM. IIAI: CHM increase insulin sensitivity and ameliorate insulin resistance; PIEI: CHM promote insulin secretion and elevate serum insulin levels; INGA: CHM inhibit $\alpha$-glucosidase activity; PIPR: CHM protect islet $\beta$ cells and promote their regeneration; IHSG: CHM increase hepatic glycogen content and suppress gluconeogenesis; INSG: CHM inhibit the secretion of glucagon; PRGU: CHM promote the glucose uptake by adipose and muscular tissues. In the figure, seven CHM examples were given. CHM may involve a variety of hypoglycemic mechanisms, and only the main mechanism is mentioned in this figure. Dotted line means the possible ways in which CHM exert hypoglycemic effects. Solid lines show potential hypoglycemic mechanisms.

(1) CHM control oxidative stress response, such as scavenging oxygen radicals, preventing lipid peroxidation, or inhibiting nitric oxide synthesis; (2) CHM regulate the activity of aldose reductase; (3) CHM block inflammatory response. Furthermore, CHM hypoglycemic effects are mainly based on IIAI, PIEI, INGA, PIPR, PRGU, and IHSG and fewer CHM are based on INSG.

\section{Discussion}

5.1. Limitations of Ancient Records and Modern Studies. First, some CHM can alleviate some symptoms of DM such as polydipsia, polyuria, and polyphagia. However, this does not necessarily mean that they are able to lower blood sugar. These drugs include Phragmites australis (Cav.) Trin. ex Steud., Alisma orientale (Sam.) Juz., and Gypsum fibrosum. Second, toxicological studies on CHM were rarely conducted or no information was available on the toxicity of CHM. Fourth, many modern clinical and experimental studies on CHM were methodologically defective, which reduces their reliability and validity. Chen et al. and $\mathrm{Li}$ et al.'s results also stated this limitation $[17,18]$.
In addition, many modern clinical researches tended to focus on curative effects rather than underlying mechanisms. Although molecular biological, immunological, and phytochemical techniques have been widely applied to study the mechanism of CHM treating DM, the nature of many components or extracts was still not very clear.

5.2. Advantages of CHM in the Treatment of DM. Although CHM have many limitations, as aforementioned, the hypoglycemic effects of some CHM were well documented, and some can effectively ameliorate certain clinical symptoms of $\mathrm{DM}$, such as polydipsia, polyuria, and polyphagia. A number of studies have shown that CHM or their extracts used in combination with western medicines work even better for the treatment of DM [19, 20]. For example, Trigonella foenumgraecum L. Saponin given together with sulphonylureas could effectively control the serum glucose, with few side effects, in DM patients whose serum glucose was not well controlled by oral administration of sulphonylureas [21].

5.3. Recommendations for Further Study of CHM for the Treatment of DM. CHM are increasingly used for the treatment 
of DM primarily because of increased awareness, on the part of patients and doctors, of their advantages, such as effectiveness, natural origin, and safety. However, in order to further extend their scope of application, the limitations of $\mathrm{CHM}$ should be avoided. More evidence-based clinical trials should be performed to substantiate the efficacy of CTM prescriptions and crude CHM for the treatment of DM. To confirm the effect of CHM on DM, larger-scale, multicentered, randomized, and controlled clinical trials are needed and statistical methods should be used in all clinical trials. Besides, the mechanisms of CHM and prescriptions should be examined at the molecular and cellular levels by fully taking advantage of the latest techniques, such as biochemical, biological, molecular biological, and immunological methods. Since adverse side effects associated with use of CHM, such as hepatotoxicity, nephrotoxicity and genotoxicity, were reported frequently, it is urgent to conduct toxicological studies on CHM. In order to achieve higher accuracy and better reproducibility, all studies on CHM should be conducted by following well-established and standardized procedures.

\section{Conclusion}

CHM used to and still play an important role in the treatment of DM in China and great progresses have been made over the last decades. A great many CHM monomer components possess antidiabetes actions. Therefore, it is of great significance to develop novel CHM for the treatment of DM and its complications. The underlying mechanism by which CHM treat DM are complicated and multifactorial and involve multiple organs; studying the effect of active monomer components of CHM might be a good starting point. It is strongly significant to pay close attention to CHM for treatment of DM and its complications.

\section{Conflict of Interests}

The authors declare that there is no conflict of interests regarding the publication of this paper.

\section{Acknowledgment}

This review was supported by the 42th China Postdoctoral Science Foundation (20070420179).

\section{References}

[1] W. Yang, J. Lu, J. Weng et al., "Prevalence of diabetes among men and women in China," The New England Journal of Medicine, vol. 362, no. 12, pp. 1090-1101, 2010.

[2] M. M. Engelgau, L. S. Geiss, J. B. Saaddine et al., "The evolving diabetes burden in the United States," Annals of Internal Medicine, vol. 140, no. 11, pp. 945-950, 2004.

[3] V. Hall, R. Thomsen, O. Henriksen, and N. Lohse, "Diabetes in Sub Saharan Africa 1999-2011: epidemiology and public health implications. A systematic review," BMC Public Health, vol. 11, article 564, 2011.
[4] S. Wild, G. Roglic, A. Green, R. Sicree, and H. King, "Global prevalence of diabetes: estimates for the year 2000 and projections for 2030," Diabetes Care, vol. 27, no. 5, pp. 1047-1053, 2004.

[5] K. M. V. Narayan, J. P. Boyle, T. J. Thompson, E. W. Gregg, and D. F. Williamson, "Effect of BMI on lifetime risk for diabetes in the U.S.," Diabetes Care, vol. 30, no. 6, pp. 1562-1566, 2007.

[6] P. Zimmet, K. G. M. M. Alberti, and J. Shaw, "Global and societal implications of the diabetes epidemic," Nature, vol. 414, no. 6865, pp. 782-787, 2001.

[7] K. M. Flegal, M. D. Carroll, C. L. Ogden, and L. R. Curtin, "Prevalence and trends in obesity among US adults, 1999-2008," the Journal of the American Medical Association, vol. 303, no. 3, pp. 235-241, 2010.

[8] P. Hossain, B. Kawar, and M. El Nahas, "Obesity and diabetes in the developing world-a growing challenge," The New England Journal of Medicine, vol. 356, no. 3, pp. 213-215, 2007.

[9] T. K. Schramm, G. H. Gislason, L. Køber et al., "Diabetes patients requiring glucose-lowering therapy and nondiabetics with a prior myocardial infarction carry the same cardiovascular risk: a population study of 3.3 million people," Circulation, vol. 117, no. 15, pp. 1945-1954, 2008.

[10] T.-T. Zhang and J.-G. Jiang, "Active ingredients of traditional Chinese medicine in the treatment of diabetes and diabetic complications," Expert Opinion on Investigational Drugs, vol. 21, no. 11, pp. 1625-1642, 2012.

[11] W. L. Li, H. C. Zheng, J. Bukuru, and N. De Kimpe, "Natural medicines used in the traditional Chinese medical system for therapy of diabetes mellitus," Journal of Ethnopharmacology, vol. 92, no. 1, pp. 1-21, 2004.

[12] W. Jia, W. Y. Gaoz, and L. D. Tang, "Antidiabetic herbal drugs officially approved in China," Phytotherapy Research, vol. 17, no. 10, pp. 1127-1134, 2003.

[13] M. B. Covington, "Traditional Chinese medicine in the treatment of diabetes," Diabetes Spectrum, vol. 14, no. 3, pp. 154-159, 2001.

[14] D. Ehling, "Oriental medicine: an introduction," Alternative Therapies in Health and Medicine, vol. 7, no. 4, pp. 71-82, 2001.

[15] R. Padiya, T. N. Khatua, P. K. Bagul, M. Kuncha, and S. K. Banerjee, "Garlic improves insulin sensitivity and associated metabolic syndromes in fructose fed rats," Nutrition and Metabolism, vol. 8, article 53, 2011.

[16] M. Thomson, H. Drobiova, K. Al-Qattan, R. Peltonen-Shalaby, Z. Al-Amin, and M. Ali, "Garlic increases antioxidant levels in diabetic and hypertensive rats determined by a modified peroxidase method," Evidence-Based Complementary and Alternative Medicine, vol. 2011, Article ID 703049, 8 pages, 2011.

[17] B. Chen, X. Zhao, Y. Guo et al., "Assessing the quality of reports about randomized controlled trials of acupuncture treatment on diabetic peripheral neuropathy," PLoS ONE, vol. 7, no. 7, Article ID e38461, 2012.

[18] W. W. Li, H. Guo, H. H. Li, L. L. Wang, H. Fu, and X. M. Wang, "Integration of traditional Chinese medicines and western medicines for treating diabetes mellitus with coronary heart disease: a systematic review," Journal of Alternative and Complementary Medicine, vol. 19, no. 6, pp. 492-500, 2013.

[19] S. A. Ziai, B. Larijani, S. Akhoondzadeh et al., "Psyllium decreased serum glucose and glycosylated hemoglobin significantly in diabetic outpatients," Journal of Ethnopharmacology, vol. 102, no. 2, pp. 202-207, 2005.

[20] L. Zhu and H. L. Li, "Therapeutic efficacy of combined Berberine and Glipizide on type 2 diabete," Journal of Clinical Research, vol. 1, p. 20, 2007. 
[21] F. R. Lu, L. Shen, Y. Qin, and L. Gao, "Clinical observation of Trigonella foenum-graecum saponin combining sulphanylureas on 36 cases of type 2 diabetes mellitus," China Journal of Chinese Materia Medica, vol. 33, no. 2, pp. 184-187, 2008.

[22] Z. Y. Lu, N. S. Zhong, Y. Xie, and P. Y. Hu, Textbook of Internal Medicine, People's Health Publishing House, Beijing, China, 7th edition, 2009.

[23] X. H. Chen, X. Bai, Y. H. Liu et al., "Anti-diabetic effects of water extract and crude polysaccharides from tuberous root of Liriope spicata var. prolifera in mice," Journal of Ethnopharmacology, vol. 122, no. 2, pp. 205-209, 2009.

[24] L. Wang, Y. Wang, D. Xu, K. Ruan, Y. Feng, and S. Wang, "MDG-1, a polysaccharide from Ophiopogon japonicus exerts hypoglycemic effects through the PI3K/Akt pathway in a diabetic KKAy mouse model," Journal of Ethnopharmacology, vol. 143, no. 1, pp. 347-354, 2012.

[25] J. Xu, Y. Wang, D. Xu, K. Ruan, Y. Feng, and S. Wang, "Hypoglycemic effects of MDG-1, a polysaccharide derived from Ophiopogon japonicas, in the ob/ob mouse model of type 2 diabetes mellitus," International Journal of Biological Macromolecules, vol. 49, no. 4, pp. 657-662, 2011.

[26] M. Liu, K. Wu, X. Mao, Y. Wu, and J. Ouyang, "Astragalus polysaccharide improves insulin sensitivity in KKAy mice: regulation of PKB/GLUT4 signaling in skeletal muscle," Journal of Ethnopharmacology, vol. 127, no. 1, pp. 32-37, 2010.

[27] X. Zhou, Y. Xu, G. Yang, and F. Li, "Increased galectin-1 expression in muscle of Astragalus polysaccharide-treated type 1 diabetic mice," Journal of Natural Medicines, vol. 65, no. 3-4, pp. 500-507, 2011.

[28] F. Zou, X. Q. Mao, N. Wang, J. Liu, and J. P. Ou-Yang, "Astragalus polysaccharides alleviates glucose toxicity and restores glucose homeostasis in diabetic states via activation of AMPK," Acta Pharmacologica Sinica, vol. 30, no. 12, pp. 1607-1615, 2009.

[29] D. Gui, J. Huang, Y. Guo et al., "Astragaloside IV ameliorates renal injury in streptozotocin-induced diabetic rats through inhibiting NF- $\kappa \mathrm{B}$-mediated inflammatory genes expression," Cytokine, vol. 61, no. 3, pp. 970-977, 2013.

[30] Y. H. Xu, L. Feng, S. S. Wang et al., "Calycosin protects HUVECs from advanced glycation end products-induced macrophage infiltration," Journal of Ethnopharmacology, vol. 137, no. 1, pp. 359-370, 2011.

[31] Z. Liu, W. Li, X. Li et al., "Antidiabetic effects of malonyl ginsenosides from Panax ginseng on type 2 diabetic rats induced by high-fat diet and streptozotocin," Journal of Ethnopharmacology, vol. 145, no. 1, pp. 233-240, 2013.

[32] W. Lee, S. Kao, I. Liu, and J. Cheng, "Increase of insulin secretion by ginsenoside Rh2 to lower plasma glucose in Wistar rats," Clinical and Experimental Pharmacology and Physiology, vol. 33, no. 1-2, pp. 27-32, 2006.

[33] K. Kim and H. Y. Kim, "Korean red ginseng stimulates insulin release from isolated rat pancreatic islets," Journal of Ethnopharmacology, vol. 120, no. 2, pp. 190-195, 2008.

[34] H. Y. Kim and K. Kim, "Regulation of signaling molecules associated with insulin action, insulin secretion and pancreatic $\beta$-cell mass in the hypoglycemic effects of Korean red ginseng in Goto-Kakizaki rats," Journal of Ethnopharmacology, vol. 142, no. 1, pp. 53-58, 2012.

[35] W. C. S. Cho, T. T. Yip, W. Chung et al., "Altered expression of serum protein in ginsenoside Re-treated diabetic rats detected by SELDI-TOF MS," Journal of Ethnopharmacology, vol. 108, no. 2, pp. 272-279, 2006.
[36] Q. Tu, J. Qin, H. Dong, F. Lu, and W. Guan, "Effects of Panax notoginoside on the expression of TGF- $\beta 1$ and Smad-7 in renal tissues of diabetic rats," Journal of Huazhong University of Science and Technology, Medical Science, vol. 31, no. 2, pp. 190193, 2011.

[37] T. H. Li, C. C. Hou, C. L. Chang, and W. C. Yang, "Antihyperglycemic properties of crude extract and triterpenes from Poria cocos," Evidence-Based Complementary and Alternative Medicine, vol. 2011, Article ID 128402, 8 pages, 2011.

[38] J. H. Hsu, Y. C. Wu, I. Liu, and J. T. Cheng, "Dioscorea as the principal herb of Die-Huang-Wan, a widely used herbal mixture in China, for improvement of insulin resistance in fructose-rich chow-fed rats," Journal of Ethnopharmacology, vol. 112, no. 3, pp. 577-584, 2007.

[39] K. He, X. Li, X. Chen et al., "Evaluation of antidiabetic potential of selected traditional Chinese medicines in STZ-induced diabetic mice," Journal of Ethnopharmacology, vol. 137, no. 3, pp. 1135-1142, 2011.

[40] D. Y. Kwon, D. S. Kim, H. J. Yang, and S. Park, “The lignan-rich fractions of Fructus Schisandrae improve insulin sensitivity via the PPAR- $\gamma$ pathways in in vitro and in vivo studies," Journal of Ethnopharmacology, vol. 135, no. 2, pp. 455-462, 2011.

[41] S. P. Li, G. H. Zhang, Q. Zeng et al., "Hypoglycemic activity of polysaccharide, with antioxidation, isolated from cultured Cordyceps mycelia," Phytomedicine, vol. 13, no. 6, pp. 428-433, 2006.

[42] W. Kan, H. Wang, C. Chien et al., "Effects of extract from solidstate fermented cordyceps sinensis on type 2 diabetes mellitus," Evidence-Based Complementary and Alternative Medicine, vol. 2012, Article ID 743107, 10 pages, 2012.

[43] C.-C. Chen, C.-Y. Hsu, C.-Y. Chen, and H.-K. Liu, "Fructus Corni suppresses hepatic gluconeogenesis related gene transcription, enhances glucose responsiveness of pancreatic betacells, and prevents toxin induced beta-cell death," Journal of Ethnopharmacology, vol. 117, no. 3, pp. 483-490, 2008.

[44] C. H. Park, J. S. Noh, T. Tanaka, K. Uebaba, E. J. Cho, and T. Yokozawa, "The effects of corni fructus extract and its fractions against $\alpha$-glucosidase inhibitory activities in vitro and sucrose tolerance in normal rats," The American Journal of Chinese Medicine, vol. 39, no. 2, pp. 367-380, 2011.

[45] X. Shu, J. Lv, J. Tao, G. Li, H. Li, and N. Ma, "Antihyperglycemic effects of total flavonoids from Polygonatum odoratum in STZ and alloxan-induced diabetic rats," Journal of Ethnopharmacology, vol. 124, no. 3, pp. 539-543, 2009.

[46] Y. F. Deng, K. He, X. L. Ye et al., "Saponin rich fractions from Polygonatum odoratum (Mill.) Druce with more potential hypoglycemic effects," Journal of Ethnopharmacology, vol. 141, no. 1, pp. 228-233, 2012.

[47] J. Z. Luo and L. Luo, "American ginseng stimulates insulin production and prevents apoptosis through regulation of uncoupling protein- 2 in cultured $\beta$ cells," Evidence-Based Complementary and Alternative Medicine, vol. 3, no. 3, pp. 365-372, 2006.

[48] W. J. Huang, H. S. Niu, M. H. Lin, J. T. Cheng, and F. L. Hsu, "Antihyperglycemic effect of catalpol in streptozotocin-induced diabetic rats," Journal of Natural Products, vol. 73, no. 6, pp. 1170-1172, 2010.

[49] H. Choi, H. Jang, T. Chung et al., "Catalpol suppresses advanced glycation end-products-induced inflammatory responses through inhibition of reactive oxygen species in human monocytic THP-1 cells," Fitoterapia, vol. 86, no. 1, pp. 19-28, 2013. 
[50] H. S. Wu, J. H. Xu, L. Z. Chen, and J. J. Sun, "Studies on anti-hyperglycemic effect and its mechanism of Dendrobium candidum," Zhongguo Zhong Yao Za Zhi, vol. 29, no. 2, pp. 160163,2004

[51] Y. Zhao, Y. Son, S. Kim, Y. Jang, and J. Lee, "Antioxidant and anti-hyperglycemic activity of polysaccharide isolated from Dendrobium chrysotoxum Lindl," Journal of Biochemistry and Molecular Biology, vol. 40, no. 5, pp. 670-677, 2007.

[52] H. Zhang, J. He, L. Yuan, and Z. Lin, "In vitro and in vivo protective effect of Ganoderma lucidum polysaccharides on alloxan-induced pancreatic islets damage," Life Sciences, vol. 73, no. 18, pp. 2307-2319, 2003.

[53] C. H. Lau, C. M. Chan, Y. W. Chan et al., "Pharmacological investigations of the anti-diabetic effect of Cortex Moutan and its active component paeonol," Phytomedicine, vol. 14, no. 11, pp. 778-784, 2007.

[54] H. Hong, Q. Wang, Z. Zhao, G. Liu, Y. Shen, and G. Chen, "Studies on antidiabetic effects of cortex Moutan polysaccharide-2b in type 2 diabetes mellitus rats," Yaoxue Xuebao, vol. 38, no. 4, pp. 255-259, 2003.

[55] D. T. Ha, T. N. Trung, T. T. Hien et al., "Selected compounds derived from Moutan Cortex stimulated glucose uptake and glycogen synthesis via AMPK activation in human HepG2 cells," Journal of Ethnopharmacology, vol. 131, no. 2, pp. 417-424, 2010.

[56] Y.-G. Li, D.-F. Ji, S. Zhong et al., "Hybrid of 1-deoxynojirimycin and polysaccharide from mulberry leaves treat diabetes mellitus by activating PDX-1/insulin-1 signaling pathway and regulating the expression of glucokinase, phosphoenolpyruvate carboxykinase and glucose-6-phosphatase in alloxan-induced diabetic mice," Journal of Ethnopharmacology, vol. 134, no. 3, pp. 961970, 2011.

[57] S. D. Klomann, A. S. Mueller, J. Pallauf, and M. B. Krawinkel, "Antidiabetic effects of bitter gourd extracts in insulin-resistant $\mathrm{db} / \mathrm{db}$ mice," British Journal of Nutrition, vol. 104, no. 11, pp. 1613-1620, 2010.

[58] S. Yibchok-Anun, S. Adisakwattana, C. Y. Yao, P. Sangvanich, S. Roengsumran, and W. H. Hsu, "Slow acting protein extract from fruit pulp of Momordica charantia with insulin secretagogue and insulinomimetic activities," Biological and Pharmaceutical Bulletin, vol. 29, no. 6, pp. 1126-1131, 2006.

[59] A. C. Keller, J. Ma, A. Kavalier, K. He, A. B. Brillantes, and E. J. Kennelly, "Saponins from the traditional medicinal plant Momordica charantia stimulate insulin secretion in vitro," Phytomedicine, vol. 19, no. 1, pp. 32-37, 2011.

[60] N. P. C. Fernandes, C. V. Lagishetty, V. S. Panda, and S. R. Naik, "An experimental evaluation of the antidiabetic and antilipidemic properties of a standardized Momordica charantia fruit extract," BMC Complementary and Alternative Medicine, vol. 7, article 29, 2007.

[61] D. Sathishsekar and S. Subramanian, "Beneficial effects of Momordica charantia seeds in the treatment of STZ-induced diabetes in experimental rats," Biological and Pharmaceutical Bulletin, vol. 28, no. 6, pp. 978-983, 2005.

[62] W. Zhang, C. Liu, P. Wang et al., "Puerarin improves insulin resistance and modulates adipokine expression in rats fed a high-fat diet," European Journal of Pharmacology, vol. 649, no. 1-3, pp. 398-402, 2010.

[63] X. Fu-Liang, S. Xiao-Hui, G. Lu, Y. Xiang-Liang, and X. Hui$\mathrm{Bi}$, "Puerarin protects rat pancreatic islets from damage by hydrogen peroxide," European Journal of Pharmacology, vol. 529, no. 1-3, pp. 1-7, 2006.
[64] N. Hamza, B. Berke, C. Cheze et al., "Preventive and curative effect of Trigonella foenum-graecum L. seeds in C57BL/6J models of type 2 diabetes induced by high-fat diet," Journal of Ethnopharmacology, vol. 142, no. 2, pp. 516-522, 2012.

[65] J. Y. Zhou and S. W. Zhou, "Protection of trigonelline on experimental diabetic peripheral neuropathy," Evidence-based Complementary and Alternative Medicine, vol. 2012, Article ID 164219, 8 pages, 2012.

[66] A. A. R. Sayed, M. Khalifa, and F. F. Abd El-Latif, "Fenugreek attenuation of diabetic nephropathy in alloxan-diabetic rats: attenuation of diabetic nephropathy in rats," Journal of Physiology and Biochemistry, vol. 68, no. 2, pp. 263-269, 2012.

[67] S. Wu, G. Wang, Z. Liu et al., "Effect of geniposide, a hypoglycemic glucoside, on hepatic regulating enzymes in diabetic mice induced by a high-fat diet and streptozotoci," Acta Pharmacologica Sinica, vol. 30, no. 2, pp. 202-208, 2009.

[68] Y. Wang, S. Huang, Y. Feng, M. Ning, and Y. Leng, "Emodin, an $11 \beta$-hydroxysteroid dehydrogenase type 1 inhibitor, regulates adipocyte function in vitro and exerts anti-diabetic effect in ob/ob mice," Acta Pharmacologica Sinica, vol. 33, no. 9, pp. 11951203, 2012.

[69] H. S. Wu, D. F. Zhu, C. X. Zhou et al., "Insulin sensitizing activity of ethyl acetate fraction of Acorus calamus L. in vitro and in vivo," Journal of Ethnopharmacology, vol. 123, no. 2, pp. 288-292, 2009.

[70] M. Si, J. Lou, C. Zhou et al., "Insulin releasing and alphaglucosidase inhibitory activity of ethyl acetate fraction of Acorus calamus in vitro and in vivo," Journal of Ethnopharmacology, vol. 128, no. 1, pp. 154-159, 2010.

[71] F. Qa'dan, E. J. Verspohl, A. Nahrstedt, F. Petereit, and K. Z. Matalka, "Cinchonain Ib isolated from Eriobotrya japonica induces insulin secretion in vitro and in vivo," Journal of Ethnopharmacology, vol. 124, no. 2, pp. 224-227, 2009.

[72] Y. Liu, X. Zhu, Q. Lu et al., “Total saponins from Rhizoma Anemarrhenae ameliorate diabetes-associated cognitive decline in rats: involvement of amyloid-beta decrease in brain," Journal of Ethnopharmacology, vol. 139, no. 1, pp. 194-200, 2012.

[73] Z. Li, D. Zuo, X. Qie, H. Qi, M. Zhao, and Y. Wu, "Berberine acutely inhibits the digestion of maltose in the intestine," Journal of Ethnopharmacology, vol. 142, no. 2, pp. 474-480, 2012.

[74] M. Wang, J. Wang, R. Tan et al., "Effect of berberine on PPAR $\alpha / N O$ activation in high glucose- and insulin-induced cardiomyocyte hypertrophy," Evidence-based Complementary and Alternative Medicine, vol. 2013, Article ID 285489, 9 pages, 2013.

[75] L. Tang, W. Wei, L. Chen, and S. Liu, "Effects of berberine on diabetes induced by alloxan and a high-fat/high-cholesterol diet in rats," Journal of Ethnopharmacology, vol. 108, no. 1, pp. 109115,2006

[76] Y. S. Lee, W. S. Kim, K. H. Kim et al., "Berberine, a natural plant product, activates AMP-activated protein kinase with beneficial metabolic effects in diabetic and insulin-resistant states," Diabetes, vol. 55, no. 8, pp. 2256-2264, 2006.

[77] L. Zhang, J. Yang, X. Chen et al., "Antidiabetic and antioxidant effects of extracts from Potentilla discolor Bunge on diabetic rats induced by high fat diet and streptozotocin," Journal of Ethnopharmacology, vol. 132, no. 2, pp. 518-524, 2010.

[78] X. Xing, Z. Zhang, X. Hu, R. Wu, and C. Xu, "Antidiabetic effects of Artemisia sphaerocephala Krasch. gum, a novel food additive in China, on streptozotocin-induced type 2 diabetic rats," Journal of Ethnopharmacology, vol. 125, no. 3, pp. 410-416, 2009. 
[79] S. B. Wang and J. P. Jia, "Oxymatrine attenuates diabetesassociated cognitive deficits in rats," Acta Pharmacologica Sinica, vol. 35, no. 3, pp. 331-338, 2014.

[80] Y. H. Li, S. P. Wen, B. P. Kota et al., "Punica granatum flower extract, a potent $\alpha$-glucosidase inhibitor, improves postprandial hyperglycemia in Zucker diabetic fatty rats," Journal of Ethnopharmacology, vol. 99, no. 2, pp. 239-244, 2005.

[81] S.-L. Huang, R.-T. Yu, J. Gong et al., "Arctigenin, a natural compound, activates AMP-activated protein kinase via inhibition of mitochondria complex I and ameliorates metabolic disorders in ob/ob mice," Diabetologia, vol. 55, no. 5, pp. 1469-1481, 2012.

[82] Y. Kang and H. Y. Kim, "Glucose uptake-stimulatory activity of Amomi Semen in 3T3-L1 adipocytes," Journal of Ethnopharmacology, vol. 92, no. 1, pp. 103-105, 2004.

[83] Y. L. Leu, Y. W. Chen, C. Y. Yang et al., "Extract isolated from Angelica hirsutiflora with insulin secretagogue activity," Journal of Ethnopharmacology, vol. 123, no. 2, pp. 208-212, 2009.

[84] S. A. Park, M. Choi, M. Kim et al., "Hypoglycemic and hypolipidemic action of Du-zhong (Eucommia ulmoides Oliver) leaves water extract in C57BL/KsJ-db/db mice," Journal of Ethnopharmacology, vol. 107, no. 3, pp. 412-417, 2006.

[85] C. Hu, J. Li, K. Cheah et al., "Effect of Sanguis draconis (a dragon's blood resin) on streptozotocin- and cytokine-induced $\beta$-cell damage, in vitro and in vivo," Diabetes Research and Clinical Practice, vol. 94, no. 3, pp. 417-425, 2011.

[86] Y. M. Li, V. H. Tran, C. C. Duke, and B. D. Roufogalis, “Gingerols of zingiber officinale enhance glucose uptake by increasing cell surface GLUT4 in cultured L6 myotubes," Planta Medica, vol. 78, no. 14, pp. 1549-1555, 2012.

[87] K. Watanabe, K. Kamata, J. Sato, and T. Takahashi, "Fundamental studies on the inhibitory action of Acanthopanax senticosus Harms on glucose absorption," Journal of Ethnopharmacology, vol. 132, no. 1, pp. 193-199, 2010.

[88] J. Fu, J. Fu, J. Yuan et al., "Anti-diabetic activities of Acanthopanax senticosus polysaccharide (ASP) in combination with metformin," International Journal of Biological Macromolecules, vol. 50, no. 3, pp. 619-623, 2012.

[89] L. M. Xiu, J. Q. Liu, X. R. Shang et al., "Discussion of Ephedra and its components improvement of diabetes," Chinese Journal of Basic Medicine in Traditional Chinese Medicin, pp. 1102-1104, 2011.

[90] I. E. Juárez-Rojop, J. C. Díaz-Zagoya, J. L. Ble-Castillo et al., "Hypoglycemic effect of Carica papaya leaves in streptozotocininduced diabetic rats," BMC Complementary and Alternative Medicine, vol. 12, article 236, 2012.

[91] N. K. Rao and S. Nammi, "Antidiabetic and renoprotective effects of the chloroform extract of Terminalia chebula Retz. seeds in streptozotocin-induced diabetic rats," BMC Complementary and Alternative Medicine, vol. 6, article 17, 2006.

[92] M. Y. Qi, K. Chen, H. R. Liu, Y. H. Su, and S. Q. Yu, "Protective effect of Icariin on the early stage of experimental diabetic nephropathy induced by streptozotocin via modulating transforming growth factor betal and type IV collagen expression in rats," Journal of Ethnopharmacology, vol. 138, no. 3, pp. 731-736, 2011.

[93] S. Qian, D. Huo, S. Wang, and Q. Qian, "Inhibition of glucoseinduced vascular endothelial growth factor expression by Salvia miltiorrhiza hydrophilic extract in human microvascular endothelial cells: evidence for mitochondrial oxidative stress," Journal of Ethnopharmacology, vol. 137, no. 2, pp. 985-991, 2011. 


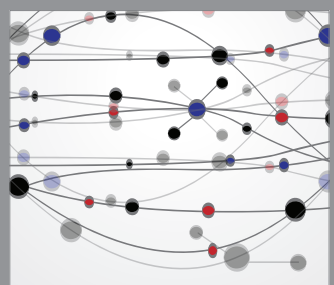

The Scientific World Journal
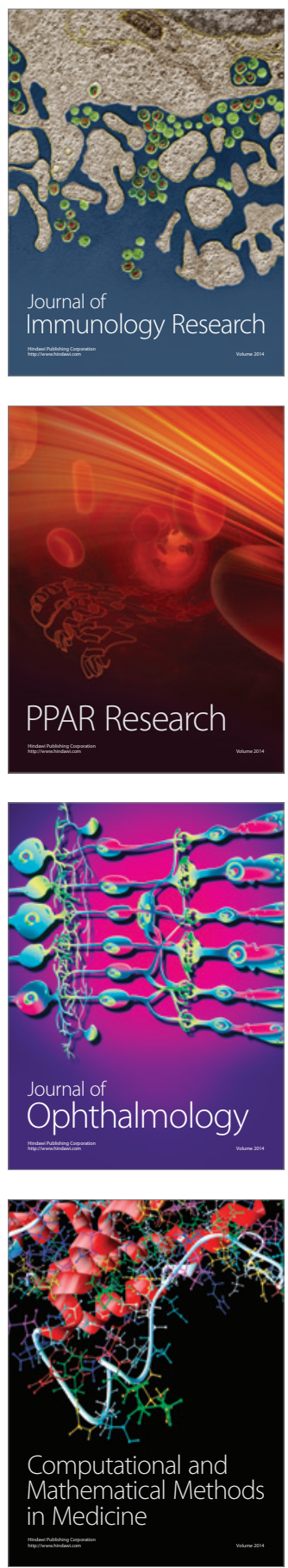

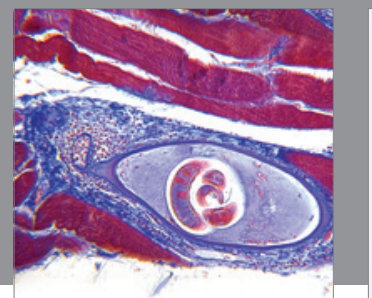

Gastroenterology

Research and Practice
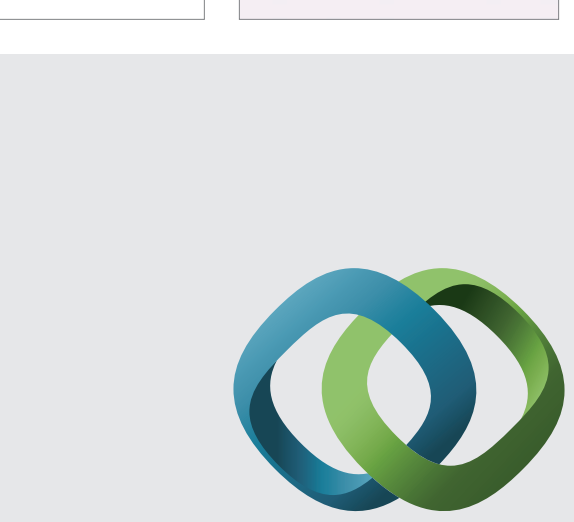

\section{Hindawi}

Submit your manuscripts at

http://www.hindawi.com
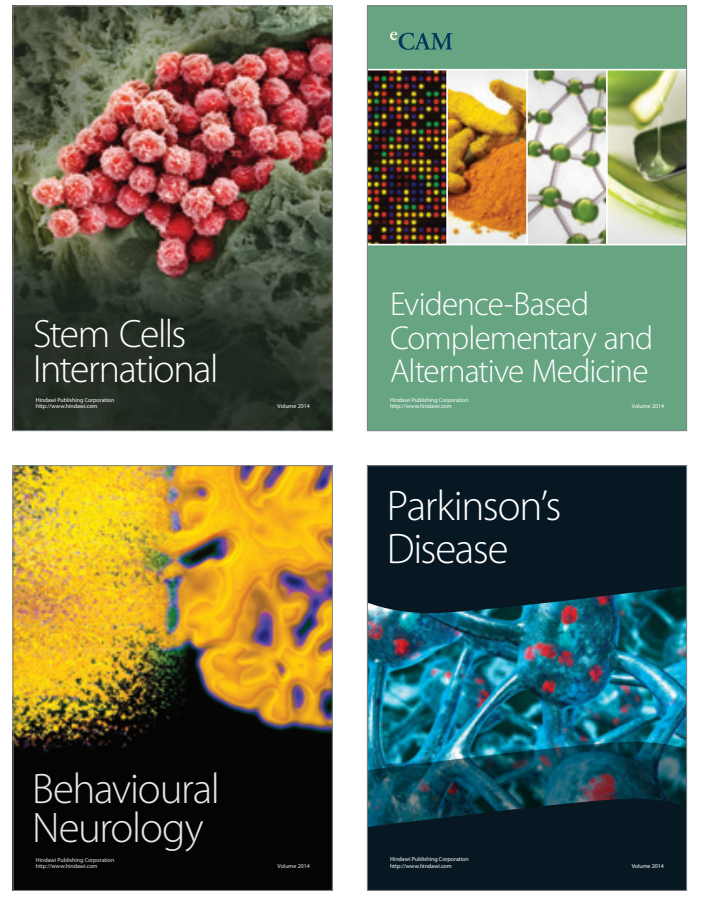
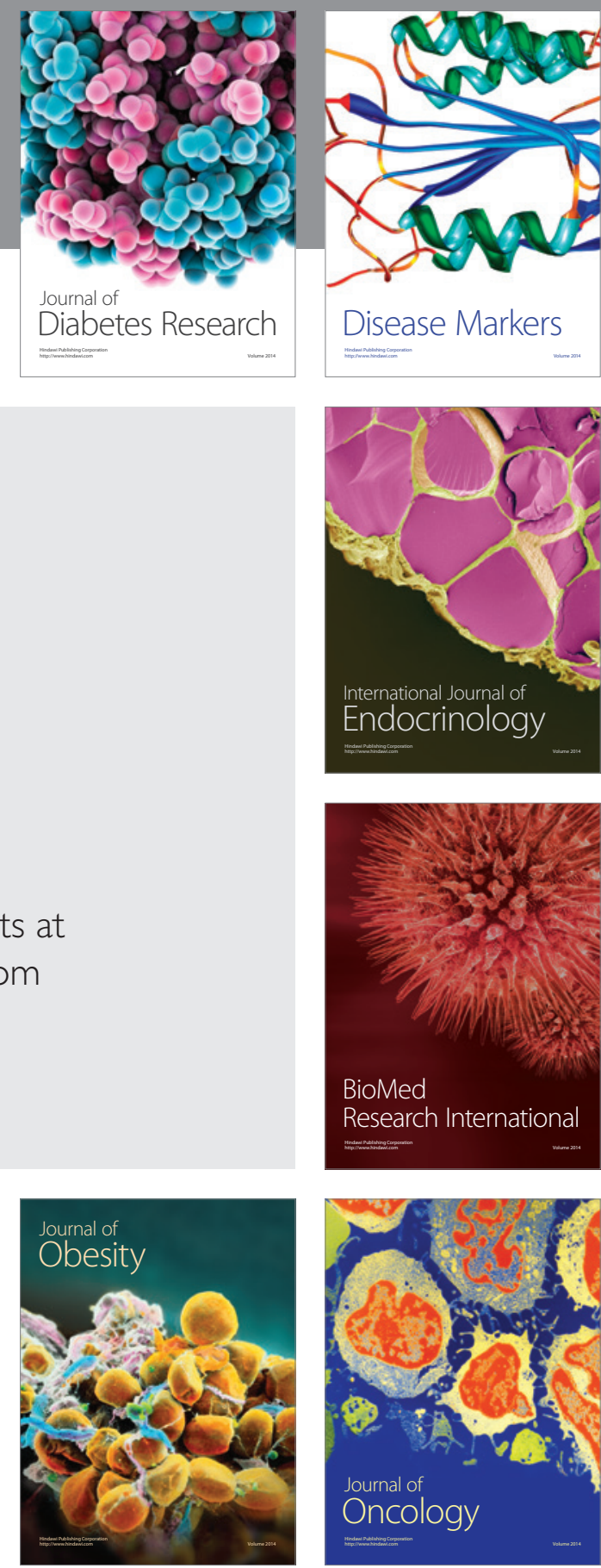

Disease Markers
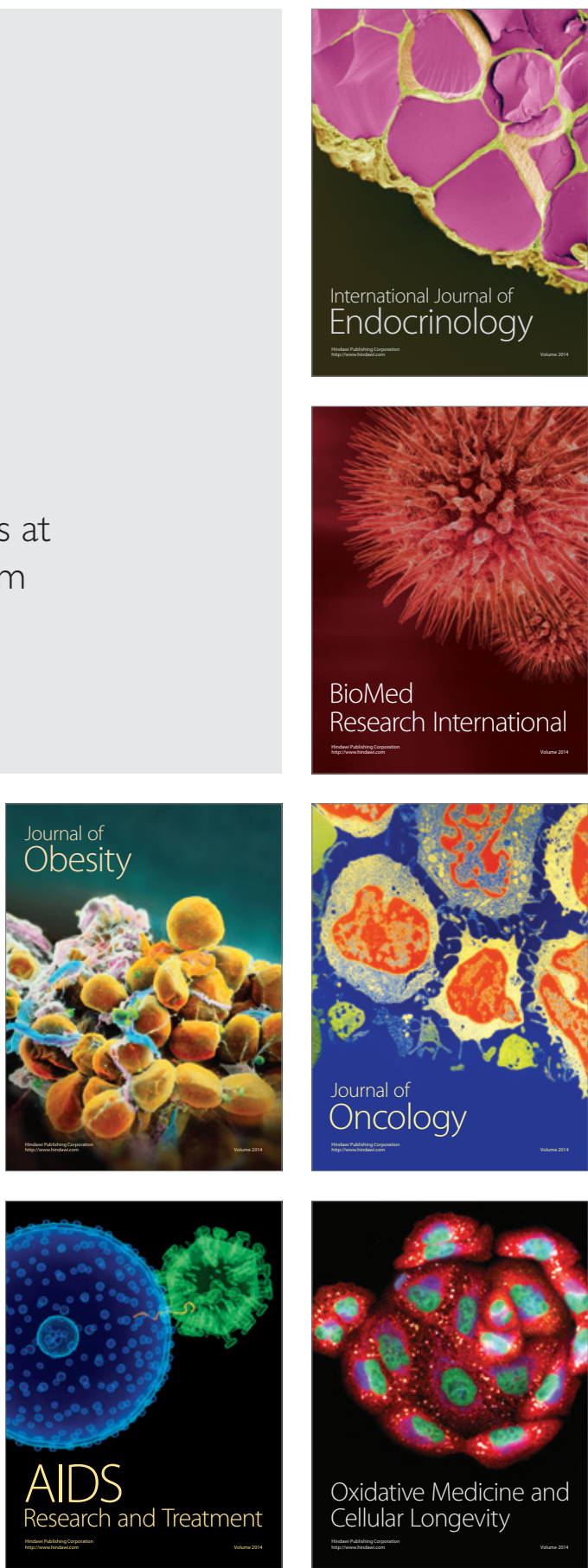